\title{
MATERNAL AND FOETAL OUTCOME IN ADHERENT PLACENTA AND ITS ASSOCIATION WITH PREVIOUS LOWER SEGMENT CAESAREAN SECTION AND HISTORY OF ABORTIONS
}

\author{
Paga Anantha Lakshmi' ${ }^{1}$ Patlolla Rajini², Banoth Damayanthi ${ }^{3}$
}

${ }^{1}$ Assistant Professor, Department of Obstetrics and Gynaecology, Osmania Medical College, Hyderabad, Telangana, India. ${ }^{2}$ Associate Professor, Department of Obstetrics and Gynaecology, Osmania Medical College, Hyderabad, Telangana, India. ${ }^{3}$ Assistant Professor, Department of Obstetrics and Gynaecology, Osmania Medical College, Hyderabad, Telangana, India.

\section{ABSTRACT}

\section{BACKGROUND}

Placenta adherence is a significant cause of maternal morbidity and mortality. Normally, the placenta adheres to decidua basalis layer, allowing for a smooth separation of the placenta from the uterus after delivery. In patients with abnormal placentation, placenta is firmly bound to the defective decidua basalis layer or even to the myometrium giving rise to varying degrees of adherent placenta.

Aim- To study the demographic profile, maternal and foetal outcome of adherent placenta with history of previous lower segment caesarean section and previous history of abortions.

\section{MATERIALS AND METHODS}

A descriptive study of 23 pregnant women with adherent placenta was conducted at Modern Government Maternity Hospital, Petlaburj, Hyderabad for a duration of 2 years, i.e. from November 2014 to November 2016.

Study Design and Sample Size- This is a retrospective study and sample size is 23.

\section{RESULTS}

In our study, $95.7 \%$ of cases were associated with placenta previa and $91.3 \%$ were associated with previous caesarean section. Thus, placenta previa compounds the risk of adherent placenta in patients with history of caesarean section. Previous history of abortions where D \& C was done is also a risk factor for adherent placenta. In our study, 7 cases (30.4) have undergone D \& C previously. Out of them, 6 (26.1) had both previous LSCS and D \& C and one patient (4.3) had history of D \& C only. She had focal adherent placenta and conservative management was done.

\section{CONCLUSION}

All cases of adherent placenta, especially placenta percreta should be managed by multidisciplinary team involving a gynaecologist and urologist. ${ }^{1}$ Preoperative cystoscopy and placement of ureteric stents may aid in identifying the ureters. ${ }^{2}$ Haemorrhage can be reduced by preoperative uterine artery balloon tamponade.

\section{KEY WORDS}

Adherent Placenta, Previous Caesarean Section, Dilatation and Curettage.

HOW TO CITE THIS ARTICLE: Lakshmi PA, Rajini P, Damayanthi B. Maternal and foetal outcome in adherent placenta and its association with previous lower segment caesarean section and history of abortions. J. Evolution Med. Dent. Sci. 2018;7(46):49434946, DOI: $10.14260 /$ jemds/2018/1100

\section{BACKGROUND}

Abnormal placentation (Accreta, Increta and Percreta) became the leading indication for peripartum hysterectomy. ${ }^{3}$ These placental abnormalities should be detected before delivery for effective management. Once a rare occurrence, morbidly adherent placenta is now becoming an increasingly common complication of pregnancy, mainly due to the increasing rate of caesarean delivery over the past years and also intrauterine procedures like dilatation and curettage, previous surgeries etc.

'Financial or Other Competing Interest': None.

Submission 29-09-2018, Peer Review 23-10-2018,

Acceptance 29-10-2018, Published 12-11-2018.

Corresponding Author:

Dr. Patlolla Rajini,

Flat No. 306, Aditya Heights,

Opposite Botanical Garden,

Kondapur,

Telangana, India.

E-mail:dr.p.rajini@gmail.com

DOI: $10.14260 /$ jemds $/ 2018 / 1100$
It is the most frequent indication for peripartum hysterectomy. In addition, the incidence of perinatal complications is also increased due to preterm birth and small for gestational age foetuses. Placenta adherence is a significant cause of maternal morbidity and mortality. Normally, the placenta adhere to decidua basalis layer allowing for a smooth separation of the placenta from the uterus after delivery. In patients with abnormal placentation, placenta is firmly bound to the defective decidua basalis layer or even the myometrium, giving rise to varying degrees of adherent placenta.

\section{Varying Degrees of Placenta Accreta}

1. Placenta Accreta Vera- placenta adheres to myometrium.

2. Placenta Increta- placenta invades the myometrium.

3. Placenta Percreta- placenta invades through the myometrium upto the uterine serosa and may include invasion into other pelvic organs like bladder, round ligament, vagina and so on.

\section{Risk Factors}

Major Risk Factors for Morbidly Adherent Placenta ${ }^{4}$ -

1. History of previous caesarean section. 
2. Anteriorly situated placenta in above situation.

3. History of dilatation and curettage.

4. Any uterine surgeries.

5. Advanced age.

6. Multiparity, etc.

\section{History of Dilatation and Curettage}

1. Any uterine surgeries.

2. Advanced age.

3. Multiparity, etc.

\section{Aims and Objectives}

\section{To Study the Demographic Profile}

Maternal and foetal outcome of adherent placenta with history of previous lower segment caesarean section and previous history of abortions.

\section{MATERIALS AND METHODS}

A descriptive study of 23 pregnant women with adherent placenta for the study was taken for convenience which was conducted at Modern Government Maternity Hospital, Petlaburj, Hyderabad for 2 years. The study included all pregnant women irrespective of parity status with gestational age more than 26 weeks who had any type of morbidly adherent placenta diagnosed on USG colour Doppler/ Magnetic Resonance Imaging (MRI) or had been diagnosed intra-operatively with morbidly adherent placenta. All patients included had delivered in our setup. The parameters studied were the mode of presentation of the patient and gestation age, history of previous lower segment/classical caesarean section or/ and other intrauterine operative procedure, dilatation and curettage, clinical presentation, maternal complications, treatment given and perinatal maternal and foetal outcome are studied and following are the results of the study.

\section{RESULTS}

\begin{tabular}{|c|c|c|c|}
\hline Parameter & & No. of Women & $\%$ \\
\hline \multirow[t]{2}{*}{ Booking Status } & Booked & 5 & 21.7 \\
\hline & Unbooked & 18 & 78.3 \\
\hline \multirow[t]{3}{*}{ Age } & $16-19$ & 0 & 0 \\
\hline & $20-30$ & 10 & 43.4 \\
\hline & $30-40$ & 13 & 56.6 \\
\hline \multirow[t]{2}{*}{ Parity } & Primigravida & 0 & 0 \\
\hline & Multigravida & 23 & 100 \\
\hline
\end{tabular}

\begin{tabular}{|c|c|c|c|}
\hline \multicolumn{2}{|l|}{ Parameter } & No. of Women & $\%$ \\
\hline \multicolumn{2}{|l|}{ Previous LSCS } & $21 / 23$ & 91.3 \\
\hline \multicolumn{2}{|c|}{ Previous LSCS with LCB $<2$ yrs. } & $14 / 21$ & 60.8 \\
\hline \multicolumn{2}{|c|}{ Previous LSCS with LCB 2 - 4 yrs. } & $5 / 21$ & 21.7 \\
\hline \multicolumn{2}{|c|}{ Previous LSCS with LCB > 4 yrs. } & $3 / 21$ & 7.3 \\
\hline \multicolumn{4}{|c|}{ Previous history of abortions } \\
\hline \multicolumn{2}{|l|}{ D \& C done } & 7 & 30.4 \\
\hline \multicolumn{2}{|l|}{ D \& C not done } & 0 & 0 \\
\hline \multicolumn{2}{|l|}{ Previous LSCS + D and C } & 6 & 26.1 \\
\hline Previous normal vaginal $\mathrm{d}$ & ivery & 1 & 4.3 \\
\hline \multicolumn{4}{|c|}{ Table 2. Previous Obstetric Performance } \\
\hline Position of Placenta & \multicolumn{2}{|c|}{ No. of Women } & $\%$ \\
\hline Upper segment & & 1 & 4.34 \\
\hline Lower segment & & & \\
\hline
\end{tabular}

\begin{tabular}{|c|c|c|}
\hline Type 1 & 0 & \\
\hline Type 2 & 1 & 4.34 \\
\hline Type 3 & 2 & 8.69 \\
\hline Type 4 & 19 & 82.5 \\
\hline \multicolumn{2}{|c|}{ Table 3. Position of Placenta } \\
\hline
\end{tabular}

\begin{tabular}{|c|c|c|}
\hline Abnormal Placentation & No. of Women & $\mathbf{\%}$ \\
\hline Focal adherent placenta & 9 & 39.1 \\
\hline Accreta & 7 & 30.4 \\
\hline Increta & 2 & 8.6 \\
\hline Percreta & 5 & 21.7 \\
\hline
\end{tabular}

\section{Table 4. Abnormal Placenta}

\begin{tabular}{|c|c|c|}
\hline Parameter & No. of Women & Percentage \\
\hline $\begin{array}{c}\text { Gestational age at time of } \\
\text { presentation }\end{array}$ & & \\
\hline$<34$ weeks & 4 & 17.4 \\
\hline 34-37 weeks & 4 & 17.4 \\
\hline$>37$ weeks & 15 & 65.2 \\
\hline APH & 9 & 39.1 \\
\hline Bleeding & 14 & 60.9 \\
\hline No bleeding & 16 & 69.5 \\
\hline Presentation of foetus & 6 & 26.08 \\
\hline Cephalic & $0 \mathrm{c}$ & 0 \\
\hline Breech & 1 & 4.34 \\
\hline Oblique & & \\
\hline Transverse & Table 5. Obstetric Evaluation \\
\hline \multicolumn{2}{|c|}{}
\end{tabular}

\begin{tabular}{|c|c|c|}
\hline Morbidity Associated & No. of Women & Percentage \\
\hline Caesarean hysterectomy & 18 & 78.26 \\
\hline Blood transfusion & 23 & 100 \\
\hline Bladder injury & 5 & 21.7 \\
\hline Uterine artery ligation & 7 & 30 \\
\hline Maternal mortality & 4 & 17.3 \\
\hline \multicolumn{2}{|c|}{ Table 6. Maternal Complications } \\
\hline
\end{tabular}

\begin{tabular}{|c|c|c|}
\hline Parameter & No. of Women & Percentage \\
\hline Term & 15 & 65.3 \\
\hline Pre-term & 8 & 34.7 \\
\hline Low birth weight <2.5 kg & & \\
\hline Term & 0 & 0 \\
\hline Preterm & 8 & 34.7 \\
\hline Perinatal mortality & 0 & 0 \\
\hline Term & 0 & 0 \\
\hline Preterm & 5 & 22 \\
\hline \multicolumn{2}{|c|}{ Table 7. Perinatal Outcome } \\
\hline
\end{tabular}

\section{Comparison of Our Study with Other Studies}

\begin{tabular}{|c|c|c|c|}
\hline \multirow{2}{*}{} & $\begin{array}{c}\text { Maplessons } \\
\text { Learnt (2012) }\end{array}$ & $\begin{array}{c}\text { Morbidly } \\
\text { Adherent } \\
\text { Placenta }\end{array}$ & Our Study \\
\cline { 2 - 4 } & $\begin{array}{c}\text { A 7-Year } \\
\text { Experience } \\
\text { (2016) }\end{array}$ & \\
\hline Booked Cases & $50 \%$ & $47.06 \%$ & $21.7 \%$ \\
\hline Gestational Age & 34.9 weeks & 36.51 weeks & 37 weeks \\
\hline \multicolumn{4}{|c|}{ At Time of Delivery } \\
\hline APH & $30 \%$ & $17.51 \%$ & $39.5 \%$ \\
\hline $\begin{array}{c}\text { Previous } \\
\text { caesarean }\end{array}$ & $100 \%$ & $76.51 \%$ & $91.3 \%$ \\
\hline \multicolumn{4}{|c|}{ Delivery Previous Caesarean } \\
\hline + D and C & $20 \%$ & $23.53 \%$ & $26.1 \%$ \\
\hline Placenta previa & $100 \%$ & $88.24 \%$ & $95.7 \%$ \\
\hline
\end{tabular}




\begin{tabular}{|c|c|c|c|}
\hline $\begin{array}{c}\text { Placenta in } \\
\text { Upper }\end{array}$ & 0 & $21.6 \%$ & $4.34 \%$ \\
\hline \multicolumn{4}{|c|}{ Segment } \\
\hline $\begin{array}{c}\text { Caesarean } \\
\text { Hysterectomy }\end{array}$ & $100 \%$ & $52.9 \%$ & $78.26 \%$ \\
\hline $\begin{array}{c}\text { Maternal } \\
\text { Mortality }\end{array}$ & $30 \%$ & $0 \%$ & $17.3 \%$ \\
\hline $\begin{array}{c}\text { Perinatal } \\
\text { Mortality }\end{array}$ & - & - & $22 \%$ \\
\hline
\end{tabular}

\section{DISCUSSION}

Adherent placenta is one of the most common reason for emergency caesarean hysterectomy and mortality rate is around $7 \%$. Previous history of Caesarean section is a major risk factor for adherent placenta. Incidence of morbidly adherent placenta is increasing secondarily to the rise of Caesarean section. In our study, $91.3 \%$ of cases of adherent placenta were associated with history of previous caesarean sections. $5,6,7$ Out of these, $60.8 \%$ of cases were associated with last child birth $<2$ years. $21.7 \%$ and $7.3 \%$ of cases with last child birth 2 - 4 years and $>4$ years respectively.

In patients of previous LSCS, posterior or not even previa should be kept in mind whether placenta is anterior or possibility of adherent placenta. In a study conducted by silver et al, the risk of adherent placenta increases from 3.3\% in patients with history of one caesarean section and placenta previa to $11 \%$ in patients with history of two caesarean sections and placenta previa to $40 \%$ with history of three caesarean sections and placenta previa.

In our study, $95.7 \%$ of cases were associated with placenta previa and $91.3 \%$ were associated with previous caesarean section. Thus, placenta previa compounds the risk of adherent placenta in patients with history of caesarean section. Increasing maternal age is also a risk factor for adherent placenta. The mean age of women in our study was around 29.9 years. Previous history of abortions where D \& C was done is also a risk factor for adherent placenta. In our study, 7 cases (30.4) have undergone D \& C previously. Out of them, 6 (26.1) had both previous LSCS and D \& C and one patient (4.3) had history of D \& C only. She had focal adherent placenta and conservative management was done. Increasing maternal age is also a risk factor for adherent placenta. The mean age of women in our study was around 29.9 years. Previous history of abortions where D \& $\mathrm{C}$ was done is also a risk factor for adherent placenta. ${ }^{8}$ In our study 7 cases (30.4) have undergone D \& C previously, out of them 6 (26.1) had both previous LSCS and D \& C and one patient (4.3) had history of D \& C only. She had focal adherent placenta and conservative management was done.

The average gestational age of delivery was around 37 weeks in our institution. Corticosteroids were given in 8 (34.7) patients for foetal lung maturity. The RCOG recommends planned delivery around $36-37$ weeks of gestation $^{9}$ with corticosteroid cover is a reasonable compromise. Individual characteristics should be considered, but with a planning needed for the especially high risk cases suspected. The average blood in our study was around $2-2.5$ litres requiring on an average of more than 5 units of packed cells and 4 units of FFPS. Generally, the recommended management of adherent placenta is planned caesarean hysterectomy with placenta left in situ, because removal of placenta is associated with significant haemorrhagic morbidity. However, surgical management of placenta may be individualised. Caesarean hysterectomy was done in 18 (78.2\%) of cases in our study, out of which 14 (77.8) cases were associated with varying degrees of placenta accreta and 4 cases were associated with focal adherent placenta. The presence of a small focal placenta accreta would allow for more conservative management. 10 The treatment generally involves applying placental bed sutures. Pre-operative prophylactic uterine artery catheterisation reduce blood loss. Haemostatic measures were uterine artery ligation and balloon tamponade. Postoperative complications of placenta accreta include DIC, fistula formation, ureteric stricture, urinary stasis, infection, pelvic and renal abscess formation, renal compromise, transfusion reaction, sepsis, ARDS and multi-organ failure. 11

In our study there were 5 cases of placenta percreta which accounts for $21 \%$ and in all the cases bladder injury occurred. In above cases there were 4 maternal deaths due to intra-operative cardiac arrest accounting for $17 \%$. There were 5 neonatal deaths, which accounts for $22 \%$ and all of them were unbooked and pre-term with antepartum haemorrhage and were delivered by emergency LSCS. Hysterectomy should be done by posterior approach dividing uterosacral ligaments and entering vagina posteriorly. Involved portion of bladder is then resected with hysterectomy specimen.

\section{CONCLUSION}

All cases of adherent placenta, especially placenta percreta should be managed by multidisciplinary team involving a gynaecologist and urologist. ${ }^{1}$ Preoperative cystoscopy and placement of ureteric stents may aid in identifying the ureters. $^{2}$ Haemorrhage can be reduced by preoperative uterine artery balloon tamponade. Multidisciplinary team and blood bank preparation may help in reducing maternal morbidity and mortality. Counselling and monitoring of patients at high risk for adherent placenta should start early in the antenatal period. ${ }^{12}$ One should resort to hysterectomy sooner rather than later.

\section{REFERENCES}

[1] Russo M, Krenz EI, Hart SR, et al. Multidisciplinary approach to the management of placenta accreta. Ochsner J 2011;11(1):84-8.

[2] Carcopino X, d'Ercole C, Bretelle F. Optimal management strategies for placenta accreta. BJOG 2009;116(11):1538-9.

[3] Palova E, Redecha M, Malova A, et al. Placenta accreta as a cause of peripartum hysterectomy. Bratislava Lek Listy 2016:117(4):212-6.

[4] Rizivi SM, Fayaz F. Demographic profile and high risk factors in morbidly adherent placenta. Int J Reprod, Contracept Obstet Gynecol 2016;5(5):1617-20.

[5] Kamara M, Henderson JJ, Doherty DA, et al. The risk if placenta accrete following elective caesarean delivery: a case-control study. BJOG 2013;120(7):879-86.

[6] Chattopadhyay SK, Kharif H, Sherbeeni MM. Placenta praevia and accreta after previous caesarean section. Eur J Obstet Gynecol Reprod Biol 1993;52(3):151-6. 
[7] Desai R, Jodha BR, Garg R. Morbidly adherent placenta and it's maternal and fetal outcome. Int J Reprod Contracept Obstet \& Gynecol 2017;6(5):1890-3.

[8] Hendricks MS, Chow YH, Bhagavath B, et al. Previous cesarean section and abortion as risk factors for developing placenta previa. J Obstet Gynaecol Res 1999;25(2):137-42.

[9] Perlman NC, Little SE, Thomas A, et al. Patient selection for later delivery timing with suspected previa-accreta. Acta Obstet Gynecol Scand 2017;96(8):1021-8.
[10] Armstrong CA, Harding S, Dickinson JE. Clinical aspects and conservative management of placenta accrete. The Obstetrician \& Gynaecologist 2004;6(3):132-7.

[11] Perez - Delboy A, Wright JD. Surgical management of placenta accrete: To leave or remove the Placenta? BJOG 2014;121(2):163-9, discussion 169-70.

[12] D'Antonio F, Palacios-Jaraquemada J, Lim PS, et al. Counseling in fetal medicine: evidence - based answers to clinical questions on morbidly adherent placenta. Ultrasound in Obstetrics \& Gyecology 2016;47(3):290301. 